\title{
Author Correction: Spontaneous synchrony in power-grid networks
}

Adilson E. Motter, Seth A. Myers, Marian Anghel and Takashi Nishikawa

Correction to: Nature Physics https://doi.org/10.1038/nphys2535, published online 10 February 2013.

In the version of this Article originally published, a normalization factor was missing in the function used to create the right side of the plot in Fig. $2 \mathrm{~b}$ (where $\beta>2$ ); that is, $\operatorname{Re} \lambda_{+}=-\beta / 2+\sqrt{\beta^{2}-4}$ was used, but it should have been $\operatorname{Re} \lambda_{+}=-\beta / 2+\sqrt{\beta^{2}-4} / 2$ (as indicated in the text). As Fig. $2 \mathrm{~b}$ was only used as an illustration, the conclusions in the Article do not change. The original and corrected Fig. $2 \mathrm{~b}$ are shown below.
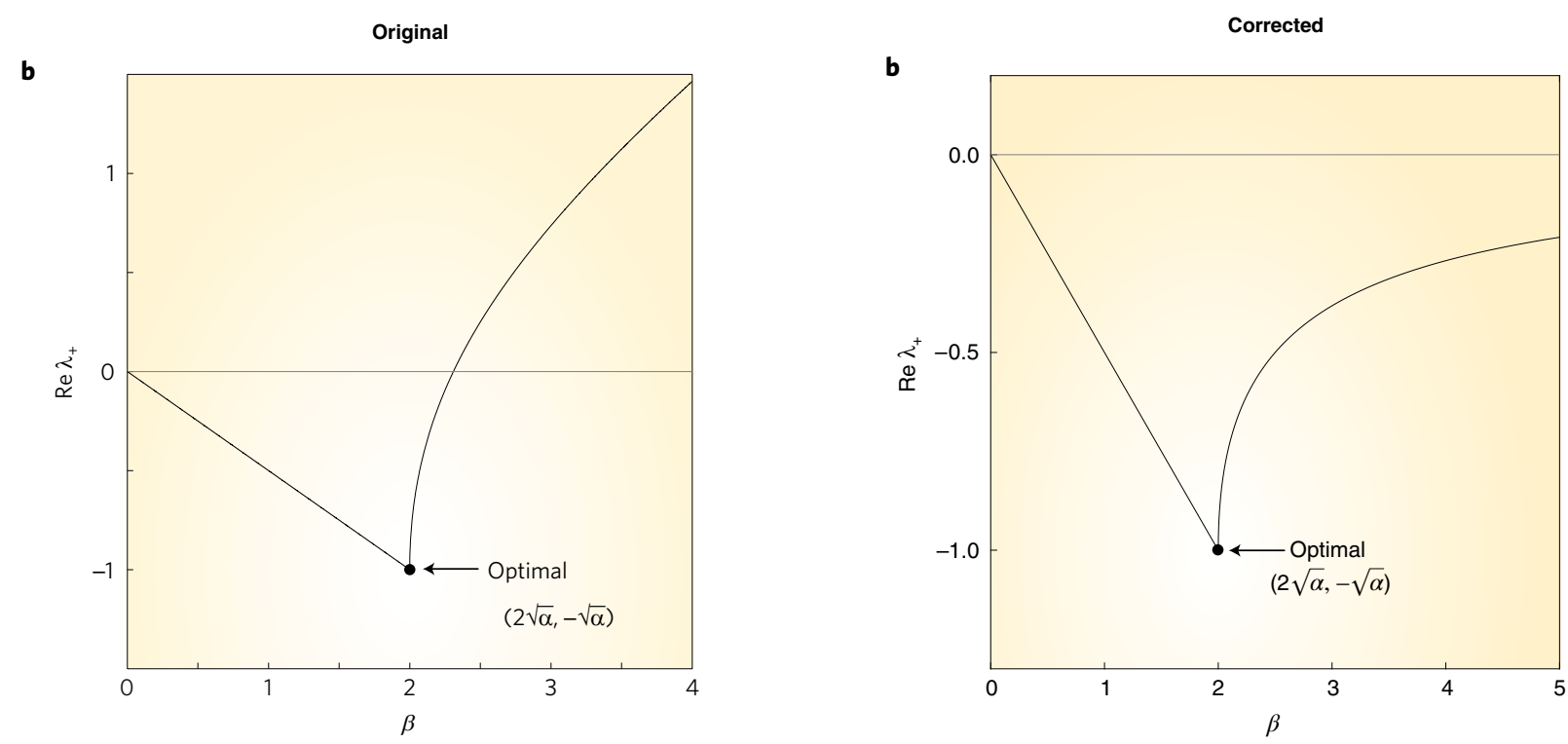

Fig. 2b

\section{Publisher Correction: Active matter: Wetting by living tissues}

Richard G. Morris and Alpha S. Yap

Correction to: Nature Physics https://doi.org/10.1038/s41567-018-0316-4, published online 24 September 2018.

In the version of this News \& Views originally published, the word 'generally' in the standfirst was incorrectly written as 'egenerally'. This has now been corrected.

Published online: 8 October 2018

https://doi.org/10.1038/s41567-018-0337-z 